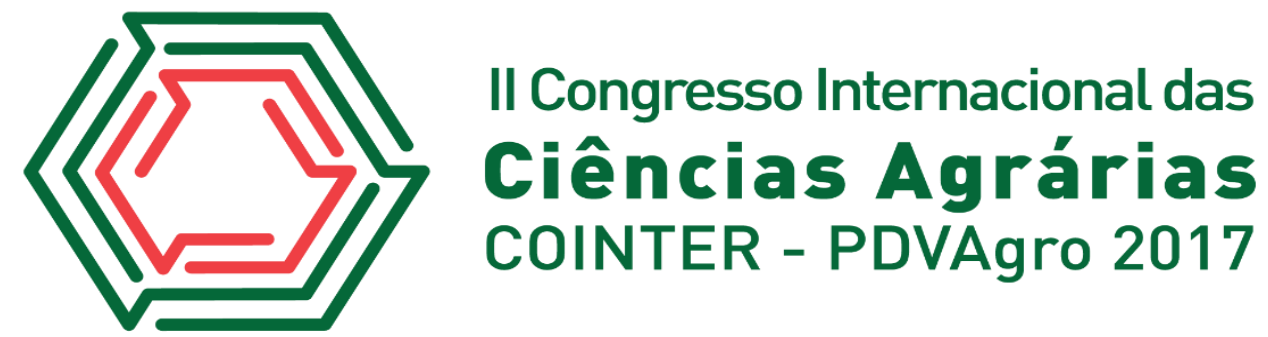

\title{
SISTEMA PRODUTIVO LOCAL: A APICULTURA NA AMAM
}

Apresentação: Relato de Experiência

Maripaula Chaveiro de Oliveira ${ }^{1}$; Pedro de Assis de Oliveira ${ }^{2}$; Marileide de Souza Sá ${ }^{3}$; João Batista Barros de Amorim ${ }^{4}$; Marcelo Casimiro Cavalcante ${ }^{5}$

\section{Introdução}

A apicultura é uma atividade que vem obtendo um crescimento econômico, social e ecológico cada vez mais em diversos países pelo mundo, onde a agricultura familiar apresenta uma grande colaboração nesse processo. A importância da apicultura e da produção de mel no município de Manari-PE, as conquistas da população e formação social dentro da comunidade, pela fundação da Associação dos Meliponicultores e Apicultores do Município de Manari- AMAM, são palco deste relato.

\section{Metodologia}

O presente trabalho foi desenvolvido numa abordagem qualitativa e quantitativa, tendo o estudo de caso da AMAM com foco na criação de abelhas Apis mellifera, sendo utilizados vários instrumentos metodológicos como: entrevistas, observações e fatos relatados pelos criadores, fornecendo dados sobre suas manifestações e o seu papel na geração de renda familiar.

A coleta de dados ocorreu durante o mês de março de 2016, sendo visitados posteriormente dois apiários localizados no sitio saquinho e sitio Minador e realizada a entrevista coletiva com 33 apicultores, para posterior tabulação dos dados e discussão da situação da apicultura no município.

\section{Relato de Experiência}

No Município de Manari-PE existe a Associação AMAM, atualmente possui 33 sócios distribuídos em diversas comunidades e distritos, entre eles: Sitio Saquinho, Umbuzeiro Doce,

\footnotetext{
${ }^{1}$ Licenciatura em Biologia, Discente do curso de Pós Graduação em Biologia Geral pela Autarquia de Ensino Superior de Arcoverde e Centro de Ensino Superior de Arcoverde- AESA-CESA, E-mail: paulinh.13@hotmail.com ${ }^{2}$ Zootecnista, Mestrando em Ciência Animal e Pastagens, Universidade Federal Rural de Pernambuco- Unidade Acadêmica de Garanhuns, E-mail: pedromanari@hotmail.com

${ }^{3}$ Licenciatura em Geografia, Bacharelando em Zootecnia, Universidade Federal Rural de Pernambuco- Unidade Acadêmica de Serra Talhada, E-mail: marileidezootecnista@hotmail.com

${ }^{4}$ Agrônomo, Mestre em Extensão Rural e Desenvolvimento Local , Universidade Federal Rural de PernambucoUnidade Acadêmica de Serra Talhada, E-mail: jbbamorim@yahoo.com.br

${ }^{5}$ Zootecnista Doutor em Zootecnia, UFRPE-UAST, E-mail: marcelufc@yahoo.com.br
} 
Minador, Alto dos Santos, Lagoa da Vaca, Bargadinha, Alto dos Santos, Serra do Exú e o Distrito de Cercadinho.

Inicialmente, ocorreu uma abordagem da vida cotidiana dos apicultores, figura principal do estudo, onde ocorreram inúmeras dificuldades: à localização dos apicultores, perspectiva de vida do povo sertanejo, as abelhas no sertão nordestino, a apicultura como renda extra sustentável familiar.

Os apicultores Manarienses perceberam nesta atividade uma forma de melhoria nas condições econômica. A apicultura na cidade de Manari teve início através dos meleiros onde o mel era comercializado de forma irregular. Diante dessa situação foram solicitados cursos ao Serviço Nacional de Aprendizagem Rural (SENAR) na área de apicultura, para os 12 sócios iniciais, onde posteriormente houve a construção da casa do mel, pela Companhia de Desenvolvimento dos Vales do São Francisco e do Parnaíba (CODEVASF), melhorando o beneficiamento do mel da AMAM (Figura 1).

Figura 1. Associação dos Meliponicultores e Apicultores do Município de Manari- (AMAM): a) Sócios recebendo equipamentos e EPI,s; b). Apicultores manejando colmeias; c) Casa do mel; d) Comercialização do mel em feiras livres. Fonte: Própria.

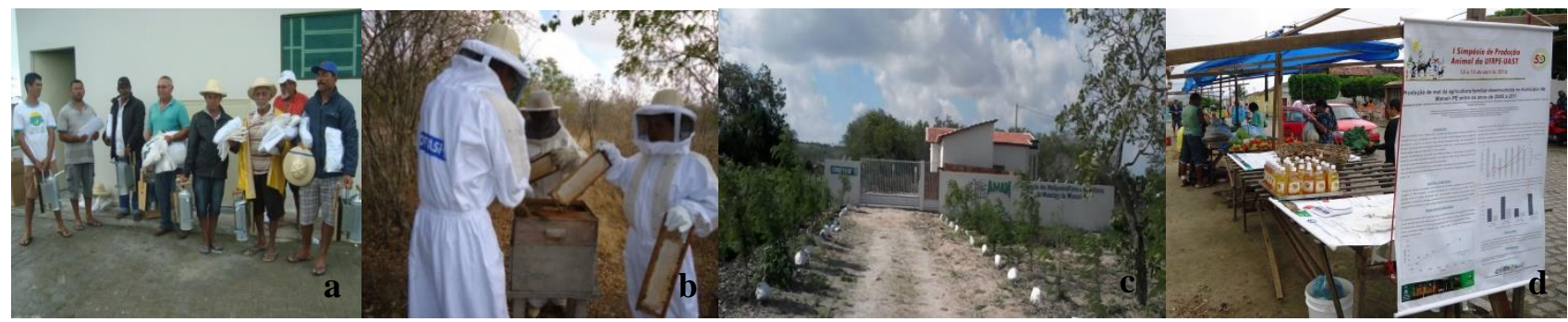

Durante muito tempo os apicultores improvisavam como podiam os seus equipamentos doados por entidades (OLIVEIRA, et al,. 2016). Os apiários foram se aperfeiçoando com novas tecnologias, expandindo a produção e comercialização em feiras locais, comércios e no Programa de Aquisição da Agricultura Familiar-PAA.

\section{Considerações}

A criação e produção apícola em Manari vem se modernizando, com acesso a novas tecnologias e ampliando como um grande meio de arranjo produtivo local e regional, tornando-se um marco de qualidade em meio à vegetação da caatinga como produto orgânico na cidade de Manari.

\section{Referências}

OLIVEIRA, P. A. et al. Produção de mel da agricultura familiar desenvolvida no município de Manari-PE entre os anos de 2005 a 2011. In: Anais.... I Simpósio de Produção Animal da UFRPEUAST, 2016, Serra Talhada-PE. 2016. 